Open Access

\title{
A quasi-qualitative analysis of flipped classroom implementation in an engineering course: from theory to practice
}

\author{
Shahid Hussain ${ }^{1 *}\left(\mathbb{D}\right.$, Prashant K. Jamwal ${ }^{2,3}$, Muhammad T. Munir ${ }^{4}$ and Aigerim Zuyeva ${ }^{2}$
}

\author{
*Correspondence: shahid.hussain@ \\ canberra.edu.au \\ ${ }^{1}$ Human-Centred Technology \\ Research Center, Faculty of Science \\ and Technology, University of \\ Canberra, Canberra, ACT, Australia \\ Full list of author information is \\ available at the end of the article
}

\begin{abstract}
Students have different learning approaches and acquire knowledge in different ways owing to their varied perceptions and grasping abilities. Treating students equally, following the traditional teacher-cantered approach, may not be effective and calls for innovations in knowledge dissemination. This article takes a studentcentric approach to implement a 'flipped classroom' model in an engineering course for constructivism (i.e. experience-based learning), and students' personalized learning. The performance of the flipped classroom approach is compared with the traditional lecturing approach using four lenses: students' grades, students' reflection using three surveys at different stages during the semester, teacher's observation, and peer observation. In most of the existing approaches, analysis of the qualitative survey data is performed manually without computer assistance, and therefore these are criticized for being primeval and instinctive. In this research, a novel approach, based on fuzzy logic, is devised to evaluate the qualitative survey responses from the students. It is shown in this research, that the linguistic survey responses can be summarized in an index more meaningfully using a fuzzy logic-based approach. The results further showed that the flipped classroom model helped students to improve their grades and enhance engagements with their teacher and their peers. Increased interaction, during interactive class activities, was instrumental in evolving students' problem-solving and critical analysis skills towards better learning experiences. Furthermore, students' survey results, analyzed using the novel fuzzy indexing and a non-parametric statistical test showed that the intervention in the form of flipped classes was effective and found to be statistically significant. The findings of this study may help other academics, endeavoring for experience-based, and students' personalized learning.
\end{abstract}

Keywords: Flipped classroom, Pedagogical model, Constructivism, Quasi-qualitative analysis, Engineering course, Theory and practice 


\section{Introduction}

A flipped classroom based pedagogical model, for constructivism (experience-based learning) and students' personalised learning, is discussed in this study to address the pedagogical problems associated with teacher-centred approaches. During a teachercentred approach, the teacher tries to transfer information to students, mainly by speaking, who listen to their teacher mostly as passive listeners, and students mostly have to work alone with limited collaboration with their peers (Mulryan-Kyne, 2010). Students are treated equally in this approach assuming that they have common learning preferences (learning by listening) and they learn at the same speed being fully engaged with the topic. Furthermore, students, owing to their limited information about the learning outcomes, walk-in with limited expectations or preparations. (Munir, Baroutian, Young, \& Carter, 2018). Following this approach, students take notes during lectures, memorise content, and gain surface learning mainly to pass exams, and rarely use higher levels of cognitivism. Formative feedback to students, or 'assessment for learning' about their learning progress, is often delayed in the teacher-centred approach until summative assessment is carried out. It is shown that the student-centric approaches, such as the flipped classroom and experience-based learning can deal with the pedagogical problems associated with teacher-centred approaches (Elen, Clarebout, Leonard, \& Lowyck, 2007; Hao \& Lee, 2016).

During the flipped classroom approach, course content is delivered to the students using a digital resource as pre-class homework, and the lecture time is used to construct knowledge through problem-solving either individually or in groups (Akçayır \& Akçayır, 2018). Following this approach, classroom activity is shifted from teachercentric to student-oriented, and students walk-in with prior information about what to expect from the session (Valero, Martinez, Pozo, \& Planas, 2018). Teachers can engage students through solving problems, using the Socratic method, or by assisting them individually based on their learning speed and preference(s) (Boyle, 2003). Furthermore, students can be self-aware about their 'assessment for learning' (i.e., formative assessment) via discussions or comparisons with their peers in the class. Following the flipped classroom approach, together with constructivism, can also help to stimulate the spontaneous use of higher-level cognitivism or deep learning. Nevertheless, the flipped classroom approach also has certain challenges, such as a considerable increase in a teacher's workload, resistance form students for accepting such intervention, before realising its actual benefits etc. (Akçayır \& Akçayır, 2018; Hutchings \& Quinney, 2015). It is interesting to note here that Gundlach, Richards, Nelson, and Levesque-Bristol (2015a, 2015b) have concluded from their study that a teacher-centred approach is better than the flipped classroom.

Constructivism, an educational learning theory, is an experience-based learning in which students construct their knowledge through observation, experience, reflecting on experiences, and connecting various ideas. It is also known as the Connectivism learning theory. During constructivism, prior knowledge acts as a foundation to construct new knowledge, whereby students actively learn to solve real-world problems through experiments. Furthermore, constructivism modifies the teacher's role from an instructor giving a series of facts to a mentor helping students to construct their knowledge. (Duffy \& Jonassen, 2013). Usually, at the university level, constructivism is used during lab-based projects or projects wherein hands-on experience is 
involved (Hay \& Barab, 2001). Constructivism has been widely discussed, in various recent studies, to assess its impact on learning and effectiveness. To cite an example, Frank, Lavy, and Elata (2003) implemented constructivism in an engineering course and concluded that students effectively constructed their knowledge through interactions with their peers and teaching staff. Hadjerrouit (2005) implemented constructivism in an engineering course and concluded that constructivism offers more learning benefits to students than objectivist instructions. Previous research has also focused on using constructivism for industrial engineering education (Miller \& Bures, 2015), collaborative learning (Schaf, Müller, Bruns, Pereira, \& Erbe, 2009), and enhancing knowledge (Kala, Isaramalai, \& Pohthong, 2010).

Various authors have previously used the flipped-classroom approach to promote student engagement during in-class sessions and have shown its effectiveness. Previously, Gilboy, Heinerichs, and Pazzaglia (2015) illustrated how to implement flipped classroom for enhancing students' engagement during in-class sessions and described students' perceptions about this approach. Bhagat, Chang, and Chang (2016) examined the effectiveness of the flipped-classroom approach on students' learning motivation and investigated its impact on their learning achievements. Similarly, Caligaris, Rodríguez, and Laugero (2016) examined students' feedback about the flipped classroom approach and found a high degree of students' acceptance to the flipped classroom rather than conventional exercises on the whiteboard. Tan, Yue, and Fu (2017), in their work, illustrated that the flipped classroom approach might help students to improve their selflearning, critical thinking, and problem-solving skills. Implementing flipped-classroom in an engineering course, Munir et al. (2018) discussed its motivations and showed that a flipped classroom is more effective than teacher-centred approach to develop students' learning skills. However, it is worth noting that most of the studies mentioned here have mainly presented implementation of a flipped classroom without comparing its effectiveness vis-à-vis traditional teaching. Previous work also did not take account of the vital indicators such as students' grades, students' reflection, teacher's observation, and peer observation. Therefore, effects of the flipped classroom to promote constructivism, and active and personalised learning in class need further investigations. Furthermore, analysis of qualitative survey questions and responses using quantitative techniques is difficult, and the existing qualitative approaches, such as proposed by Sanko, McKay, Shekhter, Motola, and Birnbach (2020), are mostly criticized for being subjective in nature and inefficient due to absence of computer assistance. Nevertheless, qualitative approaches, such as fuzzy logic, do not require conversion of survey data into crisp data for processing and analysing, and it is possible to perform requisite mathematical operations on the linguistic data.

The main objective of this study was to evaluate the efficacies of the flipped classroom pedagogy in an engineering course (Bio-mechatronics, in Mechanical Engineering) to promote constructivism besides active and personalised learning in the classroom. To achieve this objective, a digital resource of the course content, comprising texts and videos, was designed, and shared with students before the class. Students were supposed to lead the learning process by studying and watching the shared digital resource before coming to the class. During classroom sessions, the teacher facilitated the learning process by helping students through solving problems and carrying out mini-projects either individually or in groups. Students were allowed breathing room to 
reflect on learning from experience (i.e. constructivism) and from active and independent learning. After implementing flipped classroom, its effectiveness was evaluated and compared vis-à-vis traditional teaching approach. The indicators used for this comparison were students' grades using Bloom's taxonomy, students' reflections on both approaches in the form of three student surveys at different stages of the semester, teacher's observation(s), and peer observation. Furthermore, students' survey results, which were all qualitative responses, were processed by devising a fuzzy inferencing based approach. Responses, from the surveys conducted at different stages, were analysed statistically to evaluate, and establish the significance of the intervention in the form of a flipped-classroom approach.

\section{Methods}

\section{Flipped classroom model}

Course -A Bio-mechatronics course, offered at the undergraduate level, was selected to conduct this research. The course is offered by the Department of Mechanical and Mechatronics Engineering, University of Wollongong, Australia. The objective of this course is to introduce the fundamentals of bio-mechatronics, through lectures on the underlying theoretical/mechatronics aspects and application fields, in combination with tutorials/exercises. The course guides students through the design and evaluation process of mechatronic systems and highlights several applications. By the end of this course, students are expected to understand the critical elements of mechatronic systems and their interaction with the biological systems, both in terms of engineering metrics and human factors. Students should be able to apply the methods and principles learned to the design, improvement, and evaluation of safe and efficient biomechatronics systems. It is worth mentioning that under the original curriculum model, there were three one-hour lectures each week. There were 13 lectures in total during the 13 weeks semester. In total, 18 students were enrolled in the course.

\section{An overview of teaching and learning activities}

The teaching and learning activities were divided into three main parts, namely, preclass activities, class activities, and after class activities (Fig. 1). During the first lecture,

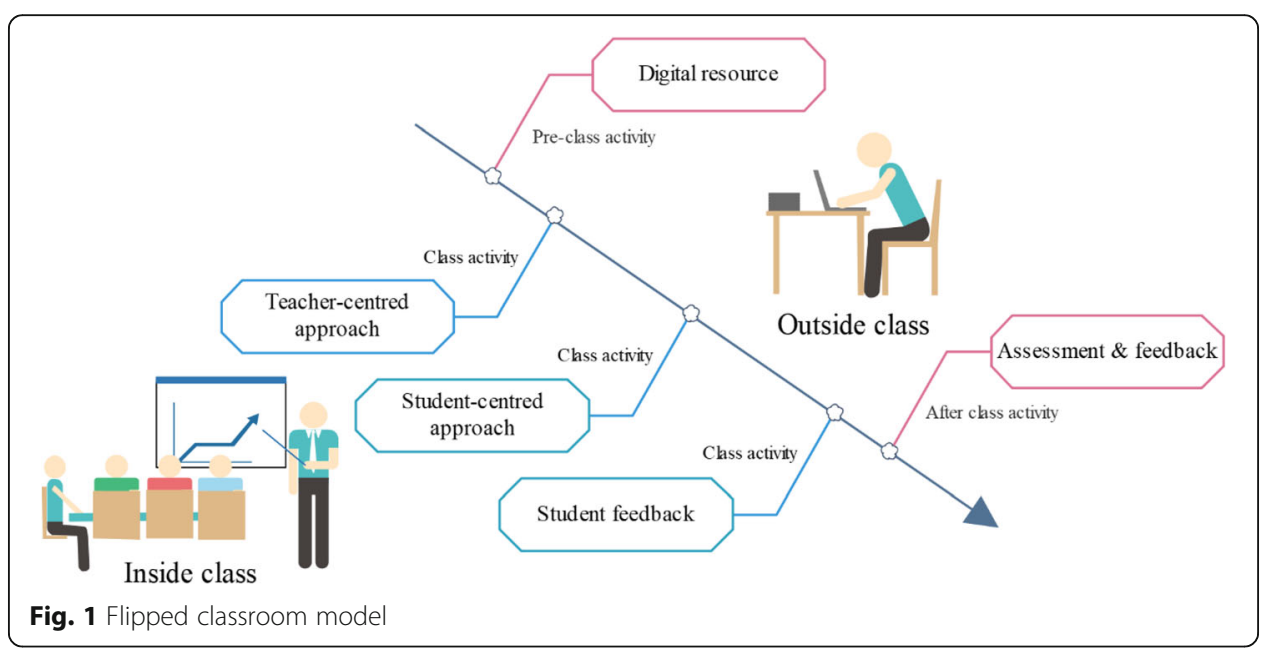


students were informed about the learning outcomes of the course and its modules, and how their performance in exams will be evaluated. Course intended learning outcomes, learning activities (before, during, and after the class), content resources or materials, and assessment tasks were all in constructive alignment for establishing transparency, achieving well organised, consistent, and explicit teaching, and learning goals.

\section{Pre-class activities}

The lecture content, commonly taught in the class, was delivered to the students in the form of pre-recorded videos through online web access before class as a pre-class activity. Videos explaining topic(s) or concept(s) of the lecture were recorded using commercial software such as Windows Live Movie Maker. Other commercially available software such as Adobe Captivate, or Screencast-O-Matic can also be used for recording videos. Pre-recorded videos were shared online with students sequentially, a set of videos every week for delivering the lecture content of that week. Shared videos were available to students until the end of the semester, and students were able to watch these videos from their mobile devices at any time. Students were advised to watch the shared videos, about the lecture content, before coming to the class. They were also asked to prepare questions which they would like to ask the teacher and discuss with their class fellows.

\section{Class activities}

A combination of teacher-centred and student-centred approaches was used in class, as shown in Fig. 1. During class sessions, interactive teaching style (i.e. student-centred) was predominantly used to actively engage students and involve them for the enhanced learning process. Various techniques were used for interactive teaching such as teacher-student interaction, student-student interaction, engaging students by using audio and visuals aids, hand-on activities, and problem-solving exercises. During teacher-student interaction, the teacher provided introductory information about the topic and recapped already shared videos to start a discussion in the class. The teacher asked questions to students to involve them in class discussions, while students tried to answer questions and asked further questions to the teacher to clarify any confusions they have. For student-student interaction in class, various techniques such as thinkpair-share and cooperative learning (i.e. team-based learning) were employed. Students were divided into small groups (maximum of three students per group) and were assigned a problem to solve as a team. Students were encouraged to interact and share their ideas and problem-solving skills to solve the assigned problem, and the teacher was there to facilitate and give feedback to students. After this group activity, student groups could share their solutions and reflections with the rest of the class for diverse opinions and thoughts. Audio and visuals aids were also used in the class to start a discussion, team-based learning, and problem-solving exercises. Hand-on activities were mainly used during the lab or tutorial sessions.

\section{After class activities}

After class or post-class activities were mainly devoted to answering students' questions, follow up discussions, and formative assessments. Students were also allowed to 
ask questions through the web accessible to students and the teacher. Every student was able to see threads of discussions. Online quizzes were conducted after the completion of each module for formative assessments and formulating students' feedback for their learning.

\section{Student assessment and constructive alignment}

Bloom's taxonomy was used predominantly for students' summative assessments. It is a systematic way of students' evaluation, in which, students' learning performance is classified into five learning levels (Bloom, 1956). It maps the way students think and process information and helps the teacher to develop a rubric for grading and discriminating students' performances at various learning levels. The five levels of Bloom's taxonomy (Fig. 2) used in this study were 1) remembering \& understanding basic knowledge of the subject, 2) applying knowledge acquired during the previous level to solve an engineering problem, 3) analysing results after applying knowledge, 4) critically reviewing and evaluating the results for judging and appraising current research activities, and 5) creating novel research. While lower levels (levels 1-3) of Bloom's taxonomy are simple and map fundamental knowledge of the subject, the higher levels (levels 4 and 5) are complex and mainly assess research and analytical skills.

Furthermore, the course was conducted in constructive alignment. Constructive alignment is a pedagogical model, in which, teaching and learning activities are aligned with assessment tasks to achieve intended learning outcomes (Biggs \& Collis, 1982). Constructive alignment, in this study, was implemented using four major steps: 1) defining the intended learning outcomes for each module, 2) designing teaching and learning activities likely to lead to the intended learning outcomes, 3) designing students' assessments to assess the intended learning outcomes, and 4) arriving at a final grade to see how well students learned the intended goals. During this study, the lecturer's intention was that majority of the students should achieve lower three levels of Bloom's taxonomy for all the modules. Assessing the next two levels was challenging because they can mainly be achieved while performing projects. The higher levels of

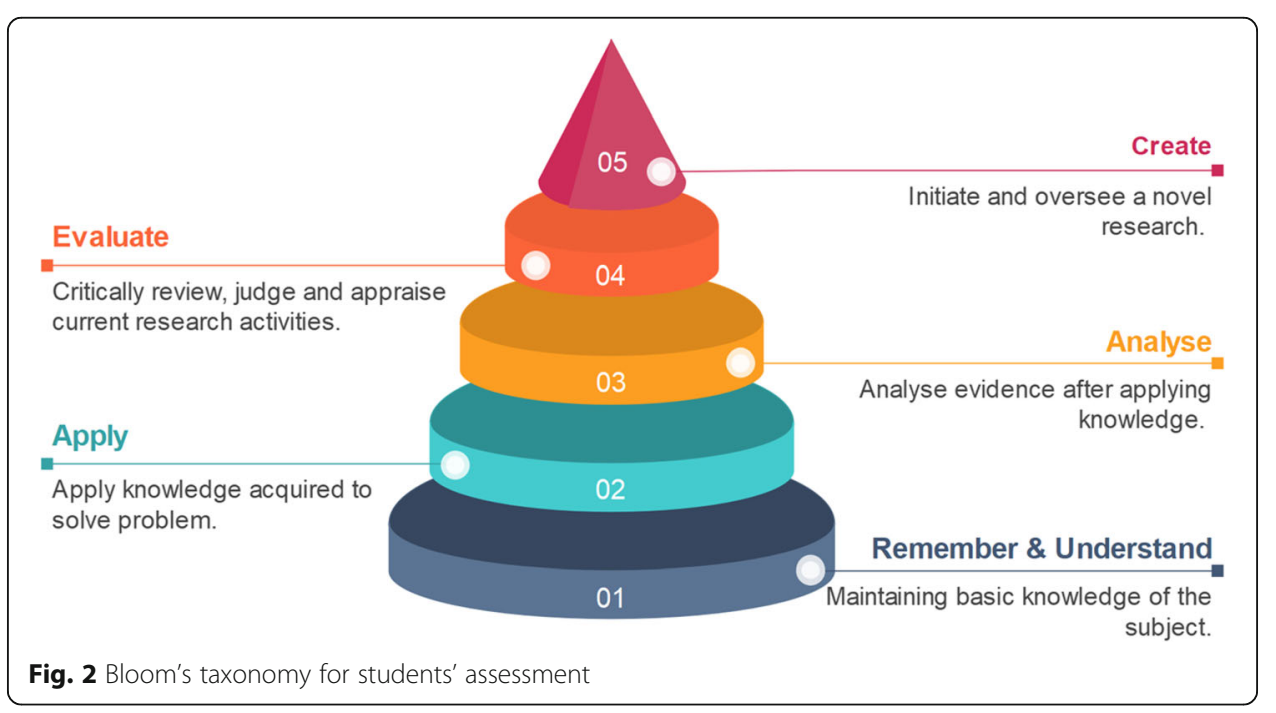


Bloom's taxonomy, in the present study, were assessed using bonus questions. It is worth mentioning that the students, on the first day of the session, were informed about the intended learning outcomes of the course, teaching and learning activities, and how their performance will be assessed.

\section{Student surveys}

In order to record students' responses, three anonymous student surveys were conducted at three different stages (during weeks 2, 7, and 13) of the semester. All 18 students enrolled in the course participated in each of the surveys. An ethics approval was obtained from the Social Sciences Human Research Ethics Committee of the University of Wollongong, Australia before collecting survey data.

During each survey, students were asked six questions to record and analyse their reflections on the effectiveness of the proposed flipped classroom model (Table 1).

Further, for each question, students were allowed to select one of the responses from six available options, namely, a) strongly agree, b) agree, c) slightly agree, d) slightly disagree, e) disagree, and f) strongly disagree. These six options, for each survey question, were designed to determine students' level of satisfaction as a response to each question. We have used a six-point Likert scale in order to avoid a neutral response which is difficult to comprehend and differentiate with a case where someone is not interested to participate. However, students were given an option to opt-out of the survey at any time.

\section{Quasi-qualitative analysis of survey data using fuzzy inferencing}

The survey responses, being all qualitative, should be analysed using appropriate tools meant for qualitative data mining. Following the usual practice of converting qualitative data into quantitative, it is more likely that some vital information will be lost or compromised. Conventional statistical methods usually fail to comprehend the inherent fuzziness of survey responses or choices and therefore may provide us with flawed analytics (Di Nardo \& Simone, 2019).

Table 1 Six questions to students about the course effectiveness

\begin{tabular}{|c|c|c|}
\hline Question \# & Detail & Multiple options \\
\hline Q1 & $\begin{array}{l}\text { Pre-class activities such as preparing before class helped me to } \\
\text { enhance my class participation and talking about ideas in class. }\end{array}$ & \multirow{6}{*}{$\begin{array}{l}\text { a) Strongly agree } \\
\text { b) Agree } \\
\text { c) Slightly agree } \\
\text { d) Slightly disagree } \\
\text { e) Disagree } \\
\text { f) Strongly disagree }\end{array}$} \\
\hline Q2 & $\begin{array}{l}\text { Class activities with peers such as talking about ideas and cooperative } \\
\text { learning with other students helped me to develop my thinking skills } \\
\text { (e.g. problem-solving and critical analysis), and communication skills. }\end{array}$ & \\
\hline Q3 & $\begin{array}{l}\text { Class activities with teachers such as teacher-student interaction } \\
\text { promoted creativity, enable new ways of critical thinking and } \\
\text { problem-solving. }\end{array}$ & \\
\hline Q4 & $\begin{array}{l}\text { After class activities such as 'students' feedback for their learning' } \\
\text { helped me to be self-aware about my learning progress compared to } \\
\text { my peers in the class. }\end{array}$ & \\
\hline Q5 & $\begin{array}{l}\text { Flipped classroom cognitive impact concept helped to develop } \\
\text { and improve students' thinking skills (e.g. problem-solving and } \\
\text { critical analysis), and communication skills. }\end{array}$ & \\
\hline Q6 & $\begin{array}{l}\text { Flipped classroom practicum impact concept helped to improve } \\
\text { constructivism or experience-based learning. }\end{array}$ & \\
\hline
\end{tabular}


Considering the above discussion, a novel quasi-qualitative analysis of the survey questionnaire based on the fuzzy logic is presented in this research. Later, using a nonparametric statistical test, the intervention of a flipped classroom is assessed. To the best of authors' knowledge, the fuzzy response evaluation approach is being proposed for the first time which is more likely to provide unbiased information and analysis of the qualitative survey data.

The responses to various survey questions received at various stages of intervention are processed using the fuzzy inferencing (Zadeh, 1965). Consequent to the application of the proposed fuzzy method, fuzzy indices are obtained for individual survey questions which are representative of the collective qualitative responses. The novel fuzzy inferencing method, for obtaining the aforementioned collective index to responses, is explained in the following Section.

\section{Fuzzy indexing}

The process of obtaining a fuzzy index for input responses has four main building blocks as shown in Fig. 3. The building blocks are, analysis of the available discrete data, fuzzification of antecedent responses and consequent fuzzy index, design of a rule-base depicting the relationship between antecedents and the consequent and devising an inference mechanism to provide a crisp consequent output which is termed as a fuzzy index in the present research. Fundamentally, there are two approaches to inferencing a fuzzy system namely, linguistic fuzzy modelling and precise fuzzy modelling (Pratihar, 2008). The linguistic fuzzy modelling, also termed as Mamdani Approach has high interpretability and the output fuzzy index represents a logical summary of all the input responses. This approach further requires a comparatively smaller database for rule-base formation and can interpret the system dynamics using discrete data. Therefore, in the present work, the Mamdani Approach for inferencing and obtaining the fuzzy index has been adopted.

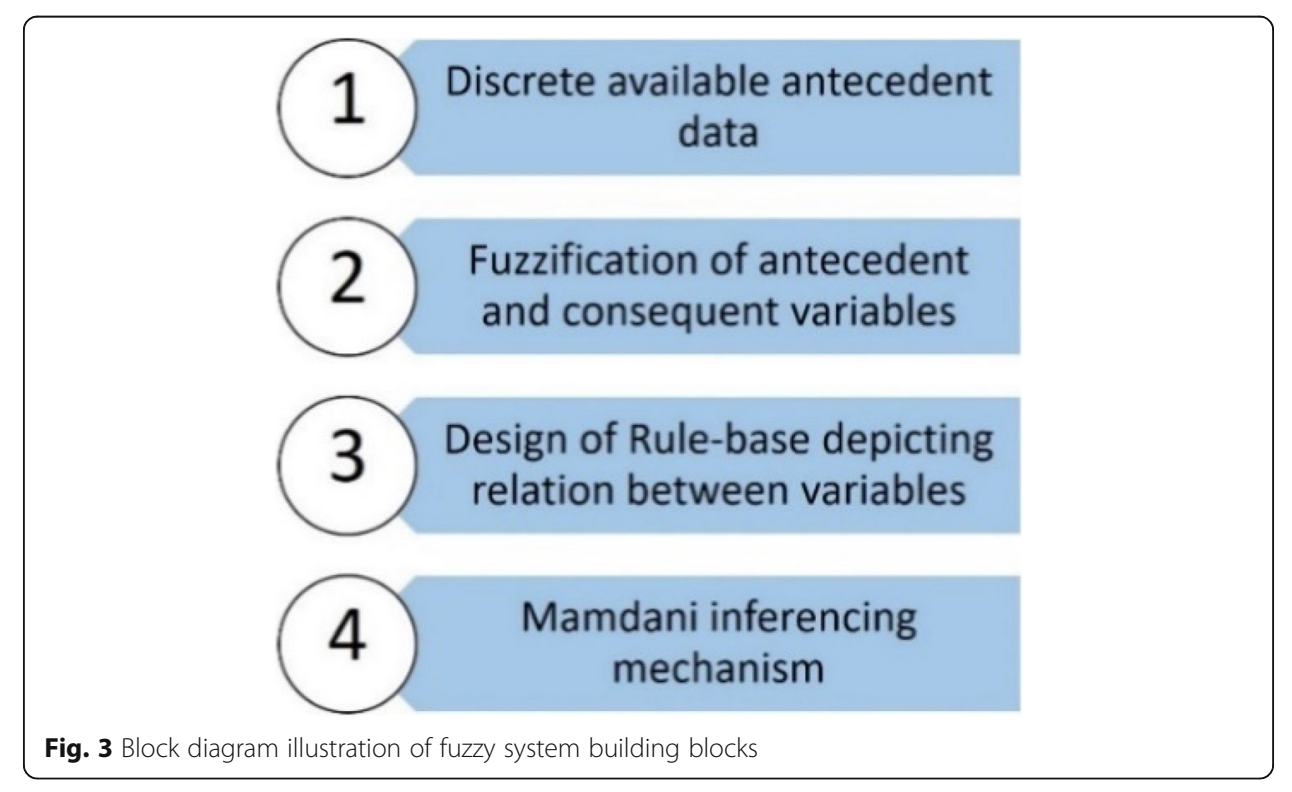


Following Mamdani's approach, the antecedent (input) responses, as well as the consequent (output) fuzzy index, are treated as fuzzy variables and later a defuzzification method is used to convert the obtained fuzzy index into a crisp index. After converting the available discrete responses to fuzzy variables (fuzzification), a rule-base in the form of if-then statements is developed intuitively relating the responses to appropriate fuzzy indices. The consolidated fuzzy indices from all the rules are finally converted into a crisp or discrete index using a defuzzification method.

\section{Fuzzification}

There are six kinds of responses in the survey questionnaire that are considered as inputs to the fuzzy inferencing. Therefore, the responses are required to be converted into fuzzy variables using fuzzy sets. Gaussian Membership Functions (MF) are selected to describe the fuzziness of these input responses.

The six input responses are denoted as Strongly Agree (SA), Agree (A), Slightly Agree (sA), Strongly Disagree (SD), Disagree (D), Slightly Disagree (sD). The two responses i.e. Strongly Agree (SA) and Strongly Disagree (SD), being more crucial, are represented by three MFs shown as Low (L), Medium (M) and High (H) in Fig. 4, while others are presented by only two MFs which are Low $(\mathrm{L})$ and High $(\mathrm{H})$. Figure 4 shows the fuzzification of input responses whereby the quantitative input responses are converted to qualitative fuzzy variables.

Increasing the number of MFs, while converting crisp variables to fuzzy variable, will exponentially increase the number of rules in the rule-base leading to an increased computational time; hence it is advised to use three or fewer numbers of MFs during fuzzification. The consequent variable or the fuzzy index is also defined as fuzzy variable in a similar fashion as shown in Fig. 5. However, for increased visibility into this

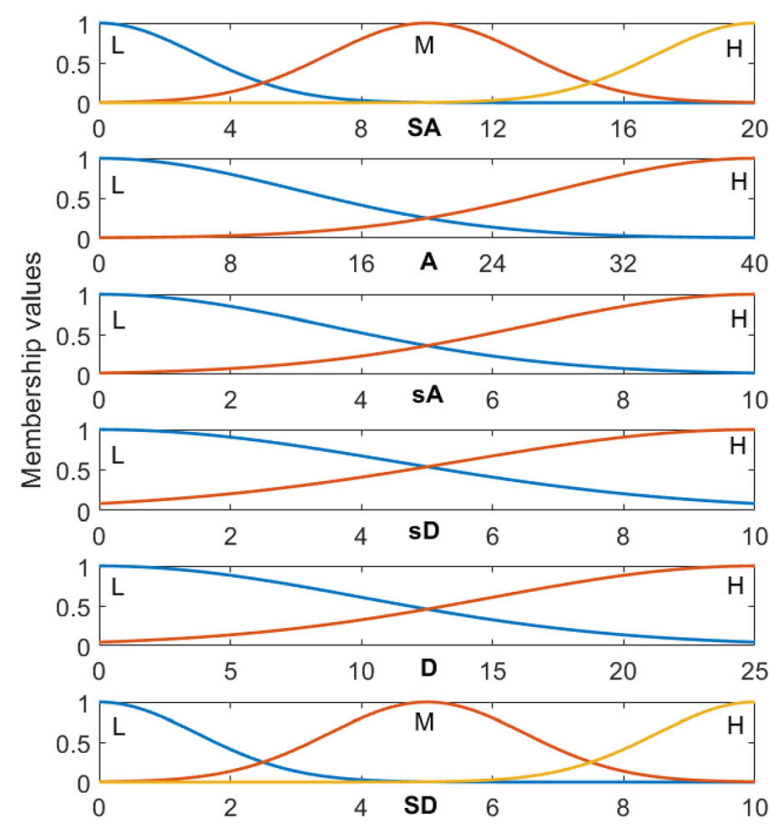

Fig. 4 Fuzzification of input survey responses 


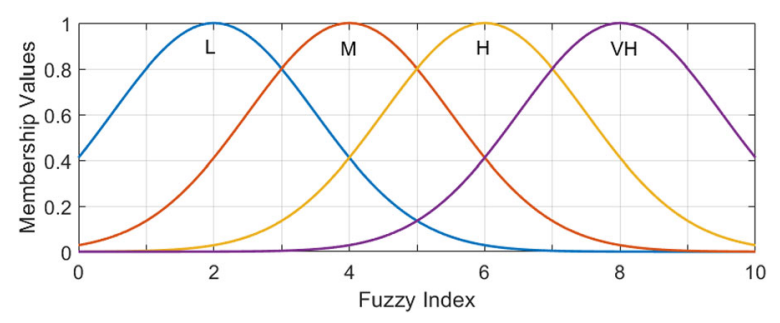

Fig. 5 Fuzzification of the output fuzzy index

index, it has been represented by four MFs and besides other notations, VH stands for a very high value of the fuzzy index.

The placements (means of the Gaussian curves) and standard deviation of the Gaussian MFs for both antecedents and the consequents are selected intuitively. The universe of discourse or the range for input responses, while converting to fuzzy variables, are selected based on the survey data obtained at three stages. This further means that the range of individual fuzzy response variable is their maximum percentage response. The range of output fuzzy index is chosen to be 10 which means that a crisp output for set of responses can vary between 0 and 10 .

\section{Rule-base}

Rule-base, as mentioned in the previous Section, consists of a collection of if-then statements connecting input responses to their anticipated fuzzy indices $(F I)$ logically as shown below:

\section{if $S A$ is $L$ and $A$ is $H$ and $s A$ is $L$ and $S D$ is $M$ and $D$ is $L$ and $S D$ is $H$ then FI is $M$}

In general, the rule is interpreted such that, if the responses have certain fuzzy (linguistic) values what will be the value of output fuzzy index $(F I)$. It is being emphasized again that the consequent $F I$ is also a fuzzy variable and not a real number. The rules are intuitively designed in such a manner that for a strong disagreement the $F I$ is penalized whereas for the strong agreement it is appreciated. In other words, a low FI indicates overall disagreement, and a higher value indicate positive response in the form of agreement to the question. The number of all possible fuzzy rules is governed by the antecedent part of the rule-base which can be given by Eq. (1) below.

Table 2 Representative five rules from the rule-base containing 144 rules, symbols have their usual meanings as (L: Low, M: Medium, H: High, VH: Very High)

\begin{tabular}{lllllll}
\hline \multicolumn{2}{l}{ Antecedent input responses } & & & & & Consequent \\
\hline SA & A & SA & SD & D & SD & index \\
\hline$L$ & $H$ & $H$ & $H$ & $H$ & $H$ & $L$ \\
$M$ & $L$ & $L$ & $H$ & $H$ & $H$ & $M$ \\
$M$ & $H$ & $H$ & $L$ & $L$ & $H$ & $H$ \\
$H$ & $H$ & $L$ & $L$ & $L$ & $H$ & $V H$ \\
$H$ & $H$ & $L$ & $L$ & $L$ & $L$ & \\
\hline
\end{tabular}




$$
R=\prod_{\mathrm{k}=1}^{\mathrm{N}} \mathrm{m}_{\mathrm{k}}
$$

Here $R$ gives the total number of rules for $N$ input variables while $m_{k}$ is the number of MFs for $k^{\text {th }}$ input variable. In the present work, there are six inputs and while two of these are defined using three MFs other four are defined using only two MFs and therefore the total number of rules is $3^{2} \times 2^{4}=144$. Few representative rules from the larger rule-base containing 144 rules are shown in Table 2.

\section{Inference engine}

In order to analyze the entire rule-base and provide a $F I$ for a given set of crisp survey responses, there exist three kinds of inference mechanisms, namely, Mamdani min-max inference, Larson product inference, and Zadeh- max-min inference (Michels, Klawonn, Kruse, \& Nurnberger, 2006). Owing to its simplicity in implementation, the Mamdani min-max inference is used in this research work (Pratihar, 2008). However, irrespective of the inferencing mechanism, initially, the crisp set of responses needs to be converted into fuzzy values using their fuzzy functions. Later, a fuzzy operator ' $\min (\wedge)$ ' is used to compute the fuzzy outputs from all the applicable rules for the input set of responses. Finally, the fuzzy outputs from all the rules are combined to provide a single fuzzy index. This fuzzy index is later defuzzified to deliver a crisp fuzzy index as shown in Table 4. Computations of the assorted fuzzy index from the rule-base can also be explained mathematically as below.

Initially, the ' $m i n$ ' operator can be applied using Equation (2) to obtain fuzzy index $\mu_{i}(F I)$ output for an individual rule $\left(i^{t h}\right)$ taking into account the given set of input responses.

$$
\mu_{i}(F I)=\mu_{i}(S A) \wedge \mu_{i}(A) \wedge \mu_{i}(s A) \wedge \mu_{i}(S D) \wedge \mu_{i}(D) \wedge \mu_{i}(s D) \wedge \mu_{i}(F I)
$$

Here $\mu_{i}$ are the MF values for the individual input responses and fuzzy index in the $i^{\text {th }}$ rule. The final fuzzy index $\mu(F I)$ is found by applying a ' $\max (\mathrm{v})$ ' operator to the outputs from the individual rules Equation (2) as shown below.

$$
\mu(F I)=\mu_{1}(F I) \vee \ldots . . \vee \mu_{R}(F I)
$$

For subsequent statistical analysis, the fuzzy index (3) needs to be converted to a crisp number, i.e. it needs to be defuzzified from a fuzzy value to a real number. There are several defuzzification methods available in the literature to this effect which are classified based on fuzzy set geometries (Hellendoorn \& Thomas, 1993) and statistical interpretations (Wierman, 1997). The centroid method, which is also called as the centre of gravity method, is used here once again owing to its simplicity in software implementation. The crisp fuzzy index $\left(F I_{0}\right)$ is nothing but the centroid value of the two dimensional shape of the fuzzy index $\mu(F I)$ which can be calculated using (4).

$$
F I_{0}=\frac{\int F I \mu(F I) d(F I)}{\int \mu(F I) d(F I)}
$$

However, in order to avoid the numerical computation of the integral Equation (4), a simplified form, equation (5), is used in the present work as below. 


$$
F I_{0}=\frac{\sum_{i=1}^{R} F I_{i} \mu\left(F I_{i}\right)}{\sum_{i=1}^{\mathrm{R}} \mu\left(F I_{i}\right)}
$$

Once again here $F I_{0}$ is the crisp fuzzy index, $F I_{i}$ are the fuzzy indices from individual rules and $\mu\left(F I_{i}\right)$ represent their MF values. The resulting crisp fuzzy indices from survey responses are calculated and tabulated (Table 4). It should be noted here that a higher value of the fuzzy index indicates students' agreement to the questions and vice-versa.

\section{Teacher's and peer observations}

\section{Teacher's observation}

During the course, the teacher looked at students' participation in teaching and learning activities, their interactions with the teacher and peers, students' grades, and their overall performance. It is worth mentioning that the same teacher had delivered the course, previously using a conventional lecture style, and later adopting the flipped classroom style.

\section{Peer observation}

Peer observation is a process where another teacher of similar field is invited to the class to spend some time observing the in-class teaching and learning strategies being used (Hammersley-Fletcher \& Orsmond, 2005). Therefore, another lecturer with extensive experience of teaching mechanical engineering students from the same department was invited to do the peer evaluations of the course during both the years. In this study, peer observation has a specific focus to look at students' interactions with their teacher and peers, students' grades, and their performance. The peer was requested to attend lectures during week 7 and week 11 in both the years.

\section{Results and discussion}

As stated above, the performance of the flipped classroom approach was compared with the traditional teaching in terms of students' grades, students' perception of the proposed teaching approach, teacher's, and peer observations. The following subsections present students' grades comparison, student survey results, and their qualitative data analysis using fuzzy logic, besides teacher's and peer observation results.

\section{Students' grades comparison}

Initially, students' grades, for the same course, were compared between the two sessions; the previous year when it was taught using conventional lecture style and later

Table 3 Students' grades comparison with and without a flipped classroom model

\begin{tabular}{lll}
\hline $\begin{array}{l}\text { Grades distribution } \\
\text { (\% marks received) }\end{array}$ & Number of students received grades & \\
\cline { 2 - 3 } & Using conventional teaching style & Using a flipped classroom model \\
\hline High distinction (85-100\%) & 01 & 02 \\
Distinction (75-84\%) & 03 & 04 \\
Credit (65-74\%) & 11 & 10 \\
Pass (50-64\%) & 05 & 02 \\
Fail (0-49\%) & 01 & 00 \\
Total students enrolled & 21 & 18 \\
\hline
\end{tabular}


when the course was delivered using the flipped classroom model. Table 3 presents students' grades distribution with and without a flipped classroom model implemented. It is worth mentioning that the number of students enrolled in the conventional lecture style was 21 , which is slightly more than the number of students enrolled (18 students) in the flipped classroom model. Students' performance was assessed using Bloom's taxonomy for both teaching styles.

It is evident from the grades displayed in Table 3 that all the enrolled students successfully passed the course when taught using a flipped classroom model. Number of students, getting a high distinction (HD) and distinction (D) grades, was also higher after the flipped classroom implementation compared to the conventional teaching style. It is interesting to note that $50 \%$ more students received a high distinction and $25 \%$ more students got distinction during a flipped classroom model than using conventional teaching style. In other words, a flipped classroom model helped high performing students more than less performing students. This is conceivable, because the flipped classroom model actively engaged the high performing students more in the teaching and learning process, which helped them to use higher levels of cognitivism spontaneously. The higher levels of cognitivism are required to achieve upper levels (Levels 4 and 5) of Bloom's taxonomy. On the other hand, conventional teaching style does not provide stimulus to use the higher levels of cognitivism. Various studies in the recent literature such as Schultz, Duffield, Rasmussen, and Wageman (2014), Abeysekera and Dawson (2015), and Hwang, Lai, and Wang (2015) have also reported similar findings of a link between using higher levels of cognitivism with flipped classroom model.

\section{Student survey and the quasi-qualitative analysis}

Survey responses and fuzzy indexing

After comparing students' grades, the opinion of students about the proposed teaching approach was collected using three surveys at three different stages (during week 2, 7, and 13) of the semester (Table 4). Survey results, owing to their qualitative nature, were analysed using fuzzy logic. The last column of Table 4 shows the fuzzy indices which are calculated after processing all the input responses (to survey questions) through a qualitative fuzzy inferencing process. The fuzzy indices, therefore, are expected to inherit all the qualitative responses in a single fuzzy number.

It is interesting to note here (Table 4) that after the first survey, during the initial weeks of the semester, a significant amount of students were against the flipped classroom pedagogical change. Though the majority of students liked constructivism or experienced-based learning. Disagreement from students was expected because the flipped classroom model was new for most of the students who were expecting course content delivery using the traditional-lecture approach. Furthermore, students may have disliked the flipped classroom model, during the early stages of the semester, because pre-class activities added additional workload on them. Various authors in recent literature, such as, Munir et al. (2018), and Gundlach et al. (2015a, 2015b) also reported similar resistance from students towards the flipped classroom model.

Nevertheless, during 2nd and 3rd surveys, students' opinions changed about the flipped classroom model, and more students started liking the pedagogical change. It appears that students took a few weeks to realise the benefits of the flipped classroom 
Table 4 Student survey results with the number and percentage of responses

\begin{tabular}{|c|c|c|c|c|c|c|c|}
\hline Question No. & $\begin{array}{l}\text { Strongly } \\
\text { Agree (SA) }\end{array}$ & Agree $(A)$ & $\begin{array}{l}\text { Slightly } \\
\text { Agree (SA) }\end{array}$ & $\begin{array}{l}\text { Slightly } \\
\text { Disagree (sD) }\end{array}$ & $\begin{array}{l}\text { Disagree } \\
\text { (D) }\end{array}$ & $\begin{array}{l}\text { Strongly } \\
\text { Disagree } \\
\text { (SD) }\end{array}$ & $\begin{array}{l}\text { Fuzzy } \\
\text { Index }\left(\left.F\right|_{0}\right)\end{array}$ \\
\hline \multicolumn{8}{|c|}{ Survey results after 2 weeks } \\
\hline Q1 & $00(0)$ & 06 (33.33) & $01(5.55)$ & $01(5.55)$ & $08(44.44)$ & $02(11.11)$ & 2.53 \\
\hline Q2 & $02(11.11)$ & $06(33.33)$ & $01(5.55)$ & $03(16.66)$ & $06(33.33)$ & $00(0)$ & 3.96 \\
\hline Q3 & $04(22.22)$ & $05(27.77)$ & $02(16.66)$ & $01(5.55)$ & $05(27.77)$ & $01(5.55)$ & 4.78 \\
\hline Q4 & $05(27.77)$ & $05(27.77)$ & $01(5.55)$ & $01(5.55)$ & $04(22.22)$ & $03(16.66)$ & 3.36 \\
\hline Q5 & $02(11.11)$ & $9(50)$ & $01(5.55)$ & $01(5.55)$ & $03(16.66)$ & $02(11.11)$ & 5.31 \\
\hline Q6 & $03(16.66)$ & $9(50)$ & $01(5.55)$ & $02(11.11)$ & $02(11.11)$ & $01(5.55)$ & 5.78 \\
\hline \multicolumn{8}{|c|}{ Survey results after 7 weeks } \\
\hline Q1 & $02(11.11)$ & $08(44.44)$ & $01(5.55)$ & $01(5.55)$ & $05(27.77)$ & $01(5.55)$ & 3.45 \\
\hline Q2 & $02(11.11)$ & $11(55.55)$ & $01(5.55)$ & $03(16.66)$ & $03(16.66)$ & $00(0)$ & 4.58 \\
\hline Q3 & $01(5.55)$ & $13(72.72)$ & $02(16.66)$ & $01(5.55)$ & $02(11.11)$ & $01(5.55)$ & 4.67 \\
\hline Q4 & $03(16.66)$ & $09(50.00)$ & $01(5.55)$ & $01(5.55)$ & $03(16.66)$ & $02(11.11)$ & 3.55 \\
\hline Q5 & $03(16.66)$ & $12(55.55)$ & $01(5.55)$ & $03(16.66)$ & $02(11.11)$ & $00(0)$ & 5.57 \\
\hline Q6 & $04(22.22)$ & $10(55.55)$ & $00(0.00)$ & $00(0)$ & $04(22.22)$ & $00(0)$ & 5.92 \\
\hline \multicolumn{8}{|c|}{ Survey results after 13 weeks } \\
\hline Q1 & $05(27.77)$ & $10(55.55)$ & $00(0)$ & $00(0)$ & $02(11.11)$ & $01(5.55)$ & 5.4 \\
\hline Q2 & $04(22.22)$ & $13(72.22)$ & $00(0)$ & $00(0)$ & $01(5.55)$ & $00(0)$ & 5.28 \\
\hline Q3 & $03(16.66)$ & $13(72.72)$ & $00(0)$ & $00(0)$ & $01(5.55)$ & $01(5.55)$ & 5.14 \\
\hline Q4 & $04(22.22)$ & $9(50)$ & $00(0)$ & $01(5.55)$ & $02(11.11)$ & $01(5.55)$ & 4.20 \\
\hline Q5 & $05(27.77)$ & $11(61.11)$ & $01(5.55)$ & $00(0)$ & $01(5.55)$ & $01(5.55)$ & 5.78 \\
\hline Q6 & 06 (33.33) & $9(50)$ & $01(5.55)$ & $00(0)$ & 01 (5.55) & $00(0)$ & 5.97 \\
\hline
\end{tabular}

model coupled with experience-based learning, such as personalised learning. Many students started enjoying the flipped classroom model during the middle and the final stages of the semester when they realised that the pedagogical change is helping them to develop new ways of problem-solving and critical thinking skills.

The crisp fuzzy indices, obtained during three assessments i.e. after weeks 2, 7, and 13, are given in Table 4 and are also plotted in Fig. 6 for more clarity. The fuzzy indices over time show an increasing trend which further exhibits growing acceptance for

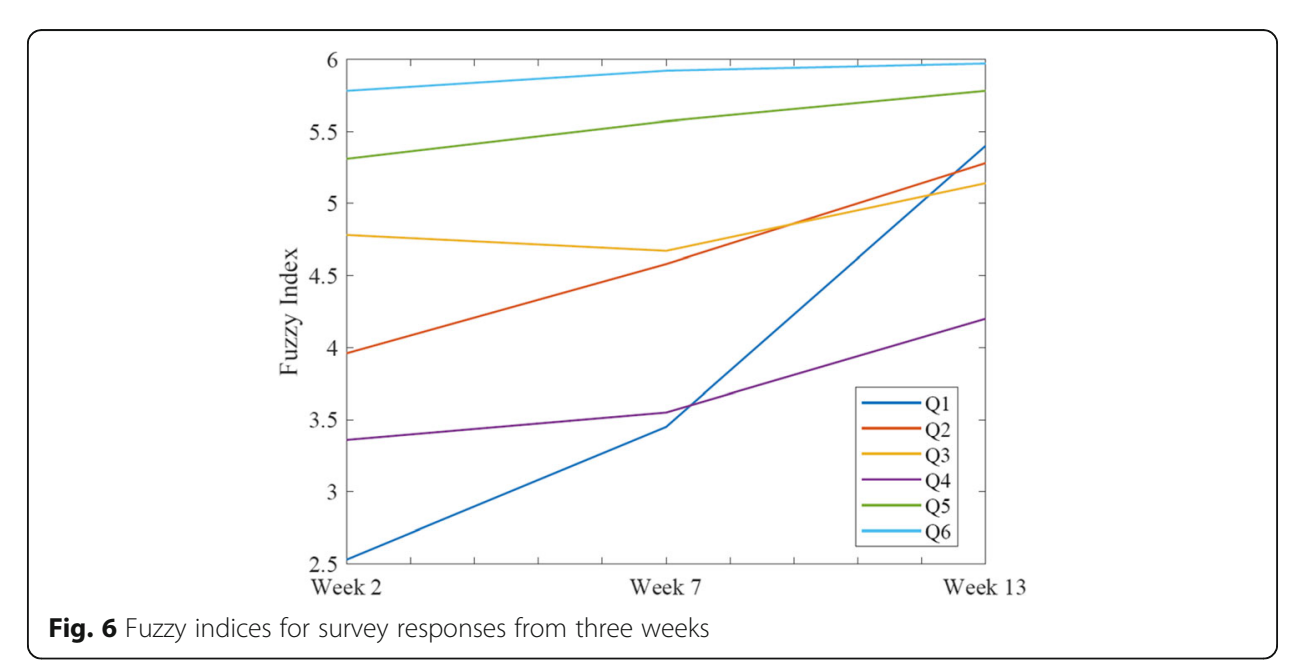


the intervention. Fuzzy indices referring to Q1 and Q2 have precipitous increase over time compared to the other questions. This further means that the pre-class and the class activities with peers during flipped class sessions have been more popular and appreciated. However, the impact of class activities with a teacher could only be realized after the seventh week. Subsequent discussions with students revealed that this was due to a gradual change in their perception about class activities with the teacher. It took some time before students could accept the fact that the teacher was not there for conventional teaching but was only scaffolding to their learning.

Next, the significance of flipped class intervention together with constructivism was evaluated using statistical methods. It can be seen that the given data do not approximate to a normal distribution and therefore a dependent samples t-test cannot be performed. Instead, one needs to use non-parametric statistical tests which are distribution-free tests. Further, since the observations and the conclusions in the form of fuzzy indices are not independent, the Mann-Whitney U-test also cannot be used. It can be concluded from the facts above that since the data come from the same population and measured on an ordinal scale, the best choice here will be to use a nonparametric statistical test called the Wilcoxon signed-rank test (Derrac, García, Molina, \& Herrera, 2011). This statistical test aims to check the significance of the difference between two sample means and thus can provide information on whether the intervention makes a significant difference. Next, the test is briefly discussed here and readers are encouraged to refer (Derrac et al., 2011) for further details.

\section{The Wilcoxon signed ranks test results}

To evaluate the significance of our intervention in the form of a flipped classroom and constructivism, the Wilcoxon signed-rank test was conducted to see if the responses between the two sets of surveys are significantly different. While comparing values of fuzzy indices between surveys conducted, let's assume that the difference between the $i^{\text {th }}$ row of the two columns is $\Delta_{i}$. Absolute values of these differences $\left(\Delta_{i}\right)$ are then ranked by ordering from smallest (lowest rank) to the highest absolute difference (largest rank). Next, the sum of ranks for positive and negative differences $\left(R_{i}^{+}, R_{i}^{-}\right)$is calculated. It is important to mention that the null hypothesis being tested here is that the median difference of the fuzzy indices between data sets is zero. The hypothesis can be quickly checked by finding the critical z-value for a two-tailed test and its directionality. At $5 \%$ level of significance $(p=0.05)$ or a $95 \%$ confidence interval this critical value is 1.96. In other words, while the sample z-value should to be 1.96 or higher, the twosided $p$-value should be less than 0.05 to reject the null hypothesis.

Various statistical measures, obtained while conducting Wilcoxon signed rank-test, are given in Table 5 for a glance. While comparing values of fuzzy indices between weeks 2 and 7, the z-value obtained is 1.9917 and the two-sided $p$-value is calculated as $p=0.0466$.

Table 5 Results from the Wilcoxon signed ranks test with a significance level of $p=0.05$

\begin{tabular}{|c|c|c|c|c|c|}
\hline \multicolumn{3}{|c|}{ Week 2 versus week 7} & \multicolumn{3}{|c|}{ Week 7 versus week 13} \\
\hline$\left(R_{i}^{+}, R_{i}^{-}\right)$ & $z$-value & $p$-Values & $\overline{\left(R_{i}^{+}, R_{i}^{-}\right)}$ & z-value & $p$-Values \\
\hline$(1,20)$ & 1.9917 & 0.0466 & $(0,21)$ & 2.2013 & 0.0272 \\
\hline
\end{tabular}


Further, a comparison between week 7 and 13 fuzzy indices gives z-value as 2.2013 leading to a two-sided $p$-value of 0.0272 . Since the $\mathrm{z}$-values are above the threshold of 1.96 and the two-sided $p$-values are well below 0.05 , the null hypothesis is rejected, or in other words, the median difference between observations during different stages of intervention is not zero. This is a shred of strong evidence that the intervention, in the form of flipped classes and constructivism, has been effective and is statistically significant.

\section{Teacher's and peer observations results}

After comparing students' grades and analysing students' survey results, teacher's observation results were considered and compared with traditional teaching results. During traditional lecturing, the teacher observed that the delivery of specific modules was well-paced, and there was no issue of on-time completion. However, there was an apparent lack of interest from the students in actively engaging with the teacher even though the teacher tried to involve students asking questions during the lectures. The reluctant behaviour of the students reflected that they probably had other learning preferences. Moreover, the teacher observed that the students were not taking enough opportunities to engage with other students, in the form of group discussions, maybe because each student learns at a different speed. This is certainly not desirable since, for a 4th-year course, the student-teacher and student-student interactive discussions are highly desirable to achieve the intended learning outcomes. Similarly, the peer also pointed out the lack of students' interest, in the subject matter, during the peerobservation of conventional teaching session. However, the peer was satisfied with the content delivery of the teacher. The peer suggested at the end of his observation in week 11 of the conventional lecture style, that the teacher could implement the flipped classroom delivery style in the following year.

During the flipped classroom approach, the teacher observed that the students' engagement with other students has significantly increased as compared to the traditional lecture-style approach. This resulted in the relatively enhanced student learning experience as well as their satisfaction. Students also learned to participate in group-level discussions which is evident in the survey results. The interaction of students with their teacher also significantly enhanced since the students were well prepared about their subject material before the class hours. A keen interest was noted among the students to discuss the pros and cons of different methods and solutions which they had discovered during their interactions with the other students.

During the flipped classroom delivery mode, the peer also observed an enhanced student interaction with the teacher besides enhanced student-student interaction and was satisfied with the outcomes of a flipped classroom delivery style. This further meant that the students had started taking control of their learning speed and learning style. The student grades were also discussed with the peer for both the conventional lecture delivery style and the flipped classroom style coupled with constructivism. The peer noticed improvements in the students' performance and recommended that, in the future, the course should be taught using the flipped classroom approach with experiencebased learning. 


\section{Conclusions}

The present study showed that the proposed flipped classroom model, coupled with constructivism or experience-based learning, was more effective than the traditional teacher-centred approach. During the present study, the flipped classroom intervention was found to be successful, since students' grades were improved and an increased number of students (approximately 75\%) received a distinction compared to the traditional approach. Moreover, despite initial resistance, students' engagement in learning activities and achieving better learning experience were significantly increased compared to the conventional teaching approach. This conclusion was drawn after analysing students' reflections during three surveys, and teacher's and peer observations. The survey results showed that a large majority of the students (approximately $80 \%$ in the third survey) were satisfied with the teaching activities, flipped classroom model, and experience-based learning. A novel quasi-qualitative analysis of the survey questionnaire based on the fuzzy logic was designed, whereby the qualitative survey answers were summarized into one fuzzy index to infer the degree of overall agreement or disagreement to survey questions. The Wilcoxon signed-rank test, of the students' survey results, showed that the flipped classroom intervention was statistically significant (with $p$ values well below the threshold of 0.05). It was concluded that the survey questionnaire can be qualitatively analysed to obtain the degree of overall agreement/disagreement using our proposed fuzzy-based approach. It is also recommended that the flipped classroom model with constructivism could be adapted, especially for engineering courses such as Bio-mechatronics, due to its additional benefits such as personalised learning and ability to minimise challenges associated with the traditional lecturing approach. Such a study is important and can help other teachers who may like to attempt improved experience-based and students' personalised learning.

\section{Limitations}

In the present study, the performance of a flipped classroom with an experience-based learning approach was evaluated using four lenses, namely, students' grades, students' reflection using three surveys at different stages of the semester, teacher's observation(s), and peer observation. However, the results of the present study mainly focused on students' reflection and satisfaction towards the flipped classroom intervention. The other three lenses were mainly used to support and validate the findings of the students' reflection. This limitation comes from the smaller number of students involved in the study, limited students' grades data available for more detailed analysis, and lack of systematic rubrics and techniques for teacher and peer observations in the recent literature. However, large students' grade data, teacher observations, and peer observations with their detailed rubrics and multiple techniques can add more value to the current findings of this study. These limitations can be addressed during future studies carried out in this direction. 


\section{Funding}

There is no funding to report for this submission.

\section{Availability of data and materials}

Not applicable.

\section{Competing interests}

The authors declare no competing interests related to this work.

\section{Author details}

${ }^{1}$ Human-Centred Technology Research Center, Faculty of Science and Technology, University of Canberra, Canberra, ACT, Australia. ${ }^{2}$ Department of Electrical and Computer Engineering, School of Engineering and Digital Sciences, Nazarbayev University, Astana, Kazakhstan. ${ }^{3}$ ReLive Research, Astana 010000, Kazakhstan. ${ }^{4}$ Department of Chemical \& Materials Engineering, Faculty of Engineering, the University of Auckland, Auckland, New Zealand.

Received: 2 October 2019 Accepted: 8 June 2020

Published online: 18 December 2020

\section{References}

Abeysekera, L., \& Dawson, P. (2015). Motivation and cognitive load in the flipped classroom: Definition, rationale and a call for research. Higher Education Research and Development, 34(1), 1-14.

Akçayır, G., \& Akçayır, M. (2018). The flipped classroom: A review of its advantages and challenges. Computers \& Education, $126,334-345$

Bhagat, K. K., Chang, C.-N., \& Chang, C.-Y. (2016). The impact of the flipped classroom on mathematics concept learning in high school. Educational Technology \& Society, 19(3), 134-142.

Biggs, J. B., \& Collis, K. F. (1982). Evaluation the quality of learning: The SOLO taxonomy (structure of the observed learning outcome). New York: Academic.

Bloom, B. S. (1956). Taxonomy of educational objectives: The classification of educational goals.

Boyle, R. A. (2003). Employing active-learning techniques and metacognition in law school: Shifting energy from professor to student. University of Detroit Mercy Law Review, 81, 1.

Caligaris, M., Rodríguez, G., \& Laugero, L. (2016). A first experience of flipped classroom in numerical analysis. Procedia - Social and Behavioral Sciences, 217, 838-845.

Derrac, J., García, S., Molina, D., \& Herrera, F. (2011). A practical tutorial on the use of nonparametric statistical tests as a methodology for comparing evolutionary and swarm intelligence algorithms. Swarm and Evolutionary Computation, 1(1), $3-18$.

Di Nardo, E., \& Simone, R. (2019). A model-based fuzzy analysis of questionnaires. Statistical Methods and Applications, 28(2), $187-215$.

Duffy, T. M., \& Jonassen, D. H. (2013). Constructivism and the technology of instruction: A conversation. Routledge

Elen, J., Clarebout, G., Leonard, R., \& Lowyck, J. (2007). Student-centred and teacher-centred learning environments: What students think. Teaching in Higher Education, 12(1), 105-117.

Frank, M., Lavy, I., \& Elata, D. (2003). Implementing the project-based learning approach in an academic engineering course. International Journal of Technology and Design Education, 13(3), 273-288.

Gilboy, M. B., Heinerichs, S., \& Pazzaglia, G. (2015). Enhancing student engagement using the flipped classroom. Journal of Nutrition Education and Behavior, 47(1), 109-114.

Gundlach, E., Richards, K. A. R., Nelson, D., \& Levesque-Bristol, C. (2015a). A comparison of student attitudes, statistical reasoning, performance, and perceptions for web-augmented traditional, fully online, and flipped sections of a statistical literacy class. Journal of Statistics Education, 23(1), 1-33.

Hadjerrouit, S. (2005). Learner-centered web-based instruction in software engineering. IEEE Transactions on Education, 48(1), 99-104.

Hammersley-Fletcher, L., \& Orsmond, P. J. S. I. H. E. (2005). Reflecting on reflective practices within peer observation. Studies in Higher Education, 30(2), 213-224.

Hao, Y., \& Lee, K. S. (2016). Teaching in flipped classrooms: Exploring pre-service teachers' concerns. Computers in Human Behavior, 57, 250-260.

Hay, K. E., \& Barab, S. A. (2001). Constructivism in practice: A comparison and contrast of apprenticeship and constructionist learning environments. The Journal of the Learning Sciences, 10(3), 281-322.

Hellendoorn, H., \& Thomas, C. (1993). Defuzzification in fuzzy controllers. Journal of Intelligent Fuzzy Systems, 1, 109-123.

Hutchings, M., \& Quinney, A. (2015). The flipped classroom, disruptive pedagogies, enabling technologies and wicked problems: Responding to" the bomb in the basement". Electronic Journal of e-learning, 13(2), 106-119.

Hwang, G.-J., Lai, C.-L., \& Wang, S.-Y. J. J. O. C. I. E. (2015). Seamless flipped learning: A mobile technology-enhanced flipped classroom with effective learning strategies. Journal of Computers in Education, 2(4), 449-473.

Kala, S., Isaramalai, S.-a., \& Pohthong, A. (2010). Electronic learning and constructivism: A model for nursing education. Nurse Education Today, 30(1), 61-66.

Michels, K., Klawonn, F., Kruse, R., \& Nurnberger, A. (2006). Fuzzy control. New York: Springer.

Miller, A., \& Bures, M. (2015). New approach to industrial engineering education with the help of interactive tools. Procedia Social and Behavioral Sciences, 174, 3413-3419.

Mulryan-Kyne, C. (2010). Teaching large classes at college and university level: Challenges and opportunities. Teaching in Higher Education, 15(2), 175-185.

Munir, M. T., Baroutian, S., Young, B. R., \& Carter, S. (2018). Flipped classroom with cooperative learning as a cornerstone. Education for Chemical Engineers, 23, 25-33.

Pratihar, D. K. (2008). Soft computing. Oxford: Alpha Science International Ltd. 
Sanko, J., McKay, M., Shekhter, I., Motola, I., \& Birnbach, D. J. (2020). What participants learn, with, from and about each other during inter-professional education encounters: A qualitative analysis. Nurse Education Today, 88, 104386.

Schaf, F. M., Müller, D., Bruns, F. W., Pereira, C. E., \& Erbe, H. H. (2009). Collaborative learning and engineering workspaces. Annual Reviews in Control, 33(2), 246-252.

Schultz, D., Duffield, S., Rasmussen, S. C., \& Wageman, J. (2014). Effects of the flipped classroom model on student performance for advanced placement high school chemistry students. Journal of Chemical Education, 91(9), 1334-1339.

Tan, C., Yue, W.-G., \& Fu, Y. (2017). Effectiveness of flipped classrooms in nursing education: Systematic review and metaanalysis. Chinese Nursing Research, 4(4), 192-200

Valero, M. M., Martinez, M., Pozo, F., \& Planas, E. (2018). A successful experience with the flipped classroom in the transport phenomena course. Education for Chemical Engineers, 4, 67-79

Wierman, M. J. (1997). Central values of fuzzy numbers - Defuzzification. Information Sciences, 100(1-4), $207-215$.

Zadeh, L. A. (1965). Fuzzy sets. Information and Control, 8, 338-353.

\section{Publisher's Note}

Springer Nature remains neutral with regard to jurisdictional claims in published maps and institutional affiliations.

Submit your manuscript to a SpringerOpen ${ }^{\circ}$ journal and benefit from:

- Convenient online submission

- Rigorous peer review

- Open access: articles freely available online

High visibility within the field

Retaining the copyright to your article

Submit your next manuscript at $\boldsymbol{\nabla}$ springeropen.com 